\title{
Process Evaluation of an Applied Neuroeconomics Extension Course in Consulting and Management Based on Kirkpatrick's Model
}

\author{
Keitiline R. Viacava ${ }^{1}$, Álvaro Vigo $^{2} \&$ Lisiane Bizarro $^{1}$ \\ ${ }^{1}$ Institute of Psychology \\ ${ }^{2}$ Institute of Mathematics and Statistics \\ Federal University of Rio Grande do Sul (UFRGS) \\ Porto Alegre, Brazil \\ E-mail: keitiline.viacava@ufrgs.br
}

Received: Nov. 29, 2016 Accepted: Dec. 14, $2016 \quad$ Published: January 1, 2017

doi:10.5296/jmr.v9i1.10374

URL: http://dx.doi.org/10.5296/jmr.v9i1.10374

\begin{abstract}
The aim of this research was to evaluate the implementation of a 5-week (15-hour) extension course in Applied Neuroeconomics, taken by 27 undergraduates (89\% from economics majors and $11 \%$ members of a junior consulting firm) at the Federal University of Rio Grande do Sul (UFRGS) in Porto Alegre, Brazil, and to identify their perception of the adequacy and applicability of the course content for consulting purposes. At the end of each class, students evaluated the current module by responding to a 10 -item questionnaire using a 5-point scale, based on Kirkpatrick's (1996) 4-level evaluation model: reaction, learning, behavior, and results. For data analysis, Pearson's chi-squared test was used, and the Clopper-Pearson (Exact) method was adopted to estimate the confidence interval for the good/excellent response proportion. The results showed correlation between the extension course and the student's perception of the adequacy and applicability of the course for all 4 levels analyzed and for all 5 modules $(p<.01)$. Students believed that they could easily transfer the acquired knowledge to the consulting practice $(p<.01)$. In sum, this process evaluation indicated that the Applied Neuroeconomics extension course was well-structured and provided neuroscientific content of both practical and theoretical value for students planning a career in economics and management consulting.
\end{abstract}

Keywords: process evaluation, extension course, applied neuroeconomics 


\section{Introduction}

The percentage of Brazilian families who report having debts is $59 \%$, with $6.8 \%$ reporting delinquency, according to November 2012 data from the National Confederation of Trade in Goods, Services, and Tourism (Confederação Nacional do Comércio de Bens, Serviços e Turismo, CNC). Part of this population seeks support in free or low-cost community financial counseling services, such as those offered at junior consultants' firms at public universities. In southernmost Brazil, more precisely in the Federal University of Rio Grande do Sul (UFRGS), students from economics programs provide this type of consultancy, as voluntary hands-on training while they are in college. Consequently, students report challenges in comprehending and managing the incongruences between what people had planned and how they actually behaved concerning their finances. One possible explanation for this difficulty is the lack of basic psychological education.

The challenges of dealing with human behavior (e.g., the tendency to discount delayed gratification, the influence of emotions on decisions, and the propensity to avoid risks) propelled students from economics programs to demand a better understanding of the psychological aspects that guide people's financial behavior, as a way to improve their practice. To attend to this request, the schools of psychology and economics at UFRGS have partnered to establish an extension course in Applied Neuroeconomics. This program was aimed at boosting the application of evidence-based neuroscientific findings and methods in consulting and management. Particularly, the course was formulated with the goal of developing psychological literacy skills in basic principles of human behavior, to help students from economics programs apply this knowledge to better understand and manage the community members' financial challenges on an individual basis. A process evaluation of the program was undertaken to guide future educational initiatives, following prior positive indications that the program could provide relevant feedback to institutions of higher education (Praslova, 2010).

Previous studies suggested that process evaluation is an effective tool to design and measure educational program features (Arthur, Bennett, Edens, \& Bell, 2003); it can capture variability in program implementation in multiple community settings, and is one way to identify why a program succeeded or failed (Cowan \& Devine, 2012). Previous emphasis has been placed on the use of process evaluations to examine the results of field-based educational interventions, not only in health-related areas (Simpson \& Scheer, 2016), but also in the fields of communication and technology (Wu, Hu, Gu, \& Lim, 2016) and aeronautics (Tian, Hu, Jiao, Luo, \& Wu, 2015).

Although the content evaluation is a more traditional part of educational programs, the evaluation we performed was based exclusively on process rather than on content. The reason for taking this approach was that the Applied Neuroeconomics extension course was extracurricular — with a focus on practice rather than theory - and it had voluntary participation. The course did not count for academic credit hours. Nevertheless, the program included lectures about the basics of neuroeconomics, which provided students with the gist of the neural and cognitive foundations of decision-making, as follows. 


\section{The Basics of Neuroeconomics}

The theoretical basis of the program had its focus on introducing the basics of neuroeconomics: a relatively new discipline that uses methods of neuroscience to identify the neural substrates associated with economic decisions (Camerer, 2013; Loewenstein, Rick, \& Cohen, 2008). Neuroeconomics considers economic decisions in the broadest possible sense (i.e., taking into account all kinds of evaluation of alternatives carried out by humans and animals, and using analytical models that are unconventional in social sciences, such as addictions or syndromes like autism) (Camerer, Loewenstein, \& Prelec, 2004). Although money is a convenient way to determine how much someone values a given resource, economics is a science that does not deal with money, but rather with the allocation of scarce resources (Zak, 2004). Economic models, in general, represent how individuals evaluate rewards and realize choices (Fehr \& Rangel, 2011; Glimcher \& Rustichini, 2004).

Neuroeconomics is an extension of the bio-economy and behavioral economics. Through the influence of the bio-economy, neuroeconomics carries with it an implicit idea derived from an evolutionary conception, namely that of men and animals as biological organisms who share some common characteristics. Through the influence of behavioral economics, neuroeconomics uses findings from cognitive and behavioral psychology to understand and model economic decision-making, while being more focused on explicit behavior. A simple way of distinguishing between bio-economics, behavioral economics and neuroeconomics is to keep in mind that the bio-economy is concerned with the study of distal causes (i.e., the behavior of ancestors), while behavioral economics is more focused on explicit actions, and neuroeconomics on the proximal or immediate causes of behavior (Zak, 2004).

Adopting a neuroeconomic perspective of information processing, one could say that every decision process involves three steps: (a) obtaining information from the environment, (b) evaluating the options, and (c) making a choice (Quartz, 2008). Each of these three tasks can be studied separately, and most importantly, they can be measured (Zak, 2004). In humans, measures are generally obtained via computerized tasks that are developed and tested to capture cognitive behaviors of interest (e.g., decisions involving risks, uncertainty, delayed reward). In general, the tasks require people to respond to a stimulus by typing a response on the computer keyboard. This motor response is actually a behavioral, rather than cognitive, measure, but for researchers that response serves as a way of deducing what is happening in the participant's mind (Quartz, 2008). Only with the advent of neuroimaging techniques and other methods in neuroscience did it become possible to analyze what happens in the brain during the performance of such work - cognitive neuroscience. Neuroeconomics does the same, but it is a broader field of study that brings together different sub-disciplines of neuroscience (e.g., neuroanatomy, neurochemistry, neurobiology, neuropsychology).

Taken all together, as voluntary financial consulting services continue to develop inside the universities, the need for psychological literacy increases as an alternative to help students from economics programs to understand why people fail in following goals. Despite the growth of the neuroeconomics field in the last two decades, scholars have just recently begun considering the possibility of applying neuroscience concepts and techniques to understand 
and address behavioral management issues (Volk \& Kohler, 2012). The main benefit of taking this approach could be expanding students' views of people's behavior as well as taking advantage of the cognitive neuroscience methods, such as the computerized tasks used as alternatives to perform individual behavioral assessments.

The purpose of the present research was to evaluate the implementation of an extension course in Applied Neuroeconomics designed to encourage the application of evidence-based neuroscientific findings and methods in financial consulting services offered voluntarily by students to the low-income community, and also to develop psychological literacy. Specifically, we wanted to know if the program had achieved its target. Thus, we hypothesized that participation in the extension course, Applied Neuroeconomics, would have an impact on students' perceptions of the adequacy and applicability of the course content for consulting purposes.

\section{Methods}

The extension course was planned and developed at the Laboratory of Experimental Psychology, Neuroscience, and Behavior (Laboratório de Psicologia Experimental, Neurociências e Comportamento, LPNeC) at the Institute of Psychology, in partnership with a junior consulting firm (Equilíbrio Assessoria Econômica) at the Faculty of Economics (Faculdade de Ciências Econômicas, FCE), all at UFRGS. The course consisted of five modules: (a) Introduction to neuroeconomics; (b) Planning a project; (c) Programming a task; (d) Analyzing the results; and (e) Presenting the results. Students were required to attend a minimum of $75 \%$ of the total course, to present a consulting intervention proposal, and to run a pilot project.

For the purpose of process evaluation, at the end of each class, students evaluated the current module by responding to a 10-item questionnaire using a 5-point scale, based on Kirkpatrick's four-level evaluation model (Kirkpatrick, 1998):

- Reaction: participants' satisfaction, with response categories ranging from "regular" to "excellent";

- Learning: participants' knowledge acquisition, improved skills, and attitude change, with response categories also ranging from "regular" to "excellent";

- Behavior: changes in participants' on-the-job behavior because of training, varying from "no" to "yes-totally"; and

- Results: final changes that occurred or may be possible due to training, ranging from "very low" to "very high."

For data analysis, Pearson's chi-squared test was used. To follow the criteria of the test, the extreme categories of the 5-point scale were collapsed into a 3-point scale, thus leaving three response categories ("very weak/weak," "neutral," and "good/excellent"). The Clopper-Pearson (1934) Exact method was used to estimate the confidence interval for the good/excellent response proportion. The Statistical Analysis System (SAS) version 9.3 was used, and a significance level of 5\% was adopted. 


\section{Results}

The results of the adherence analyses suggested an association between the extension course in Applied Neuroeconomics and the students' perceptions of the adequacy and applicability of the course for all four levels of the questionnaire and for all five modules $(p<.01)$. The reaction (Figure 1) and learning (Figure 2) results demonstrated that students' perception of the adequacy and applicability of the course decreased in the third class. The same was not observed for the behavior (Figure 3) and results (Figure 4) categories, which remained consistent throughout the five classes. Regarding the applicability, by the end of each class, students reported that they could easily transfer the acquired knowledge to the consulting practice $(\mathrm{p}<.01)$. In the fifth (and last) module, the response proportion in the good/excellent category for the results was $82 \%$ (CI 95\%: 56.7 - 96.2).

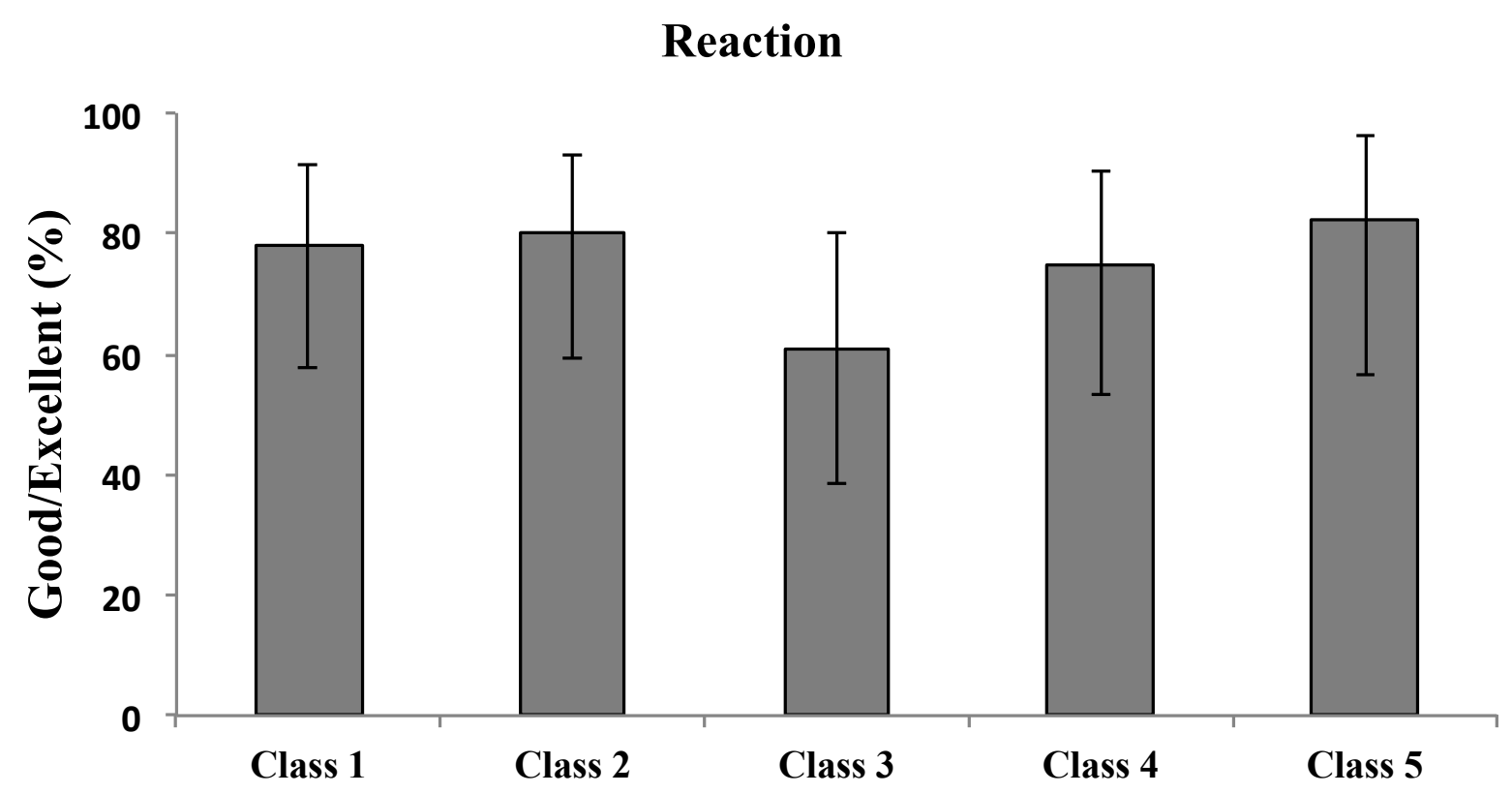

Figure 1. Reaction $=$ participants' satisfaction . 


\section{Learning}

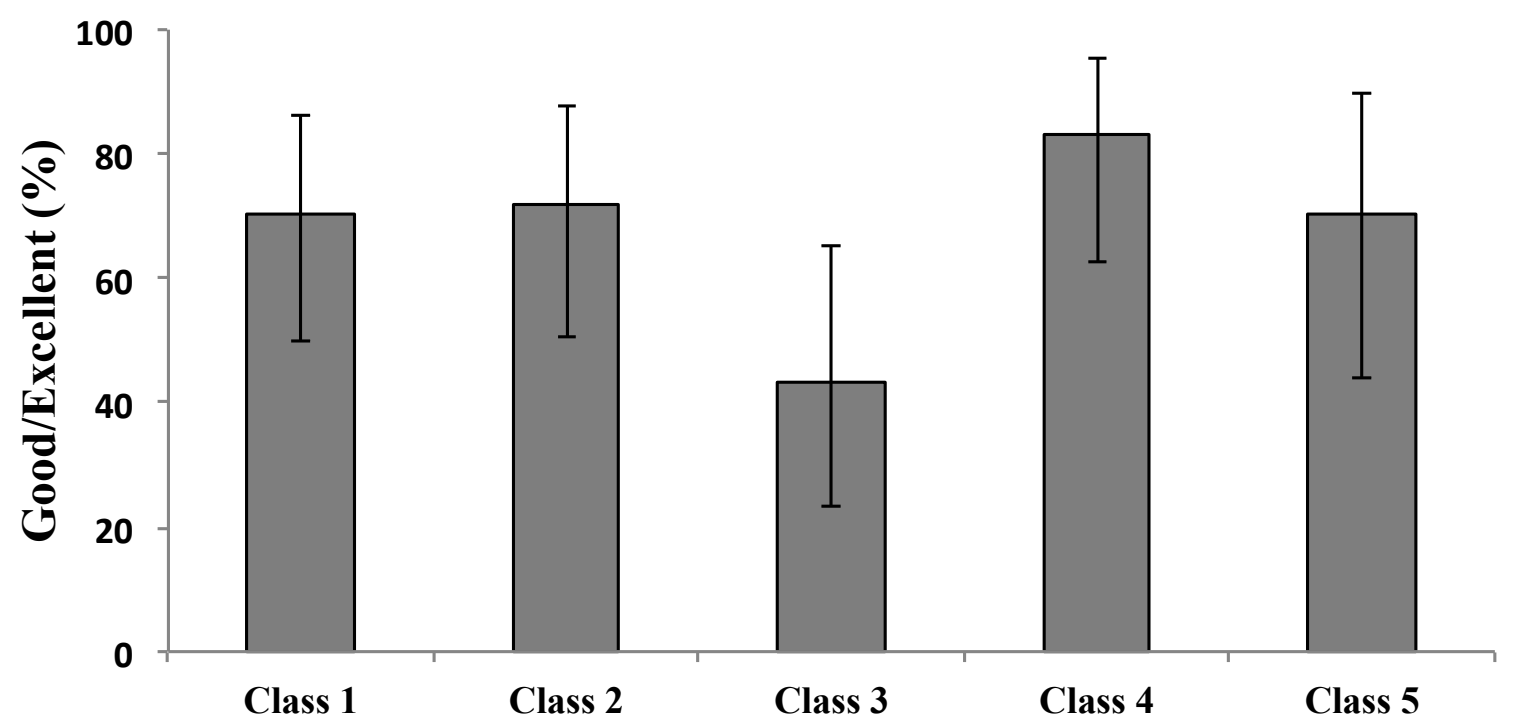

Figure 2. Learning = participants' knowledge acquisition, improved skills, and attitude change.

\section{Behavior}

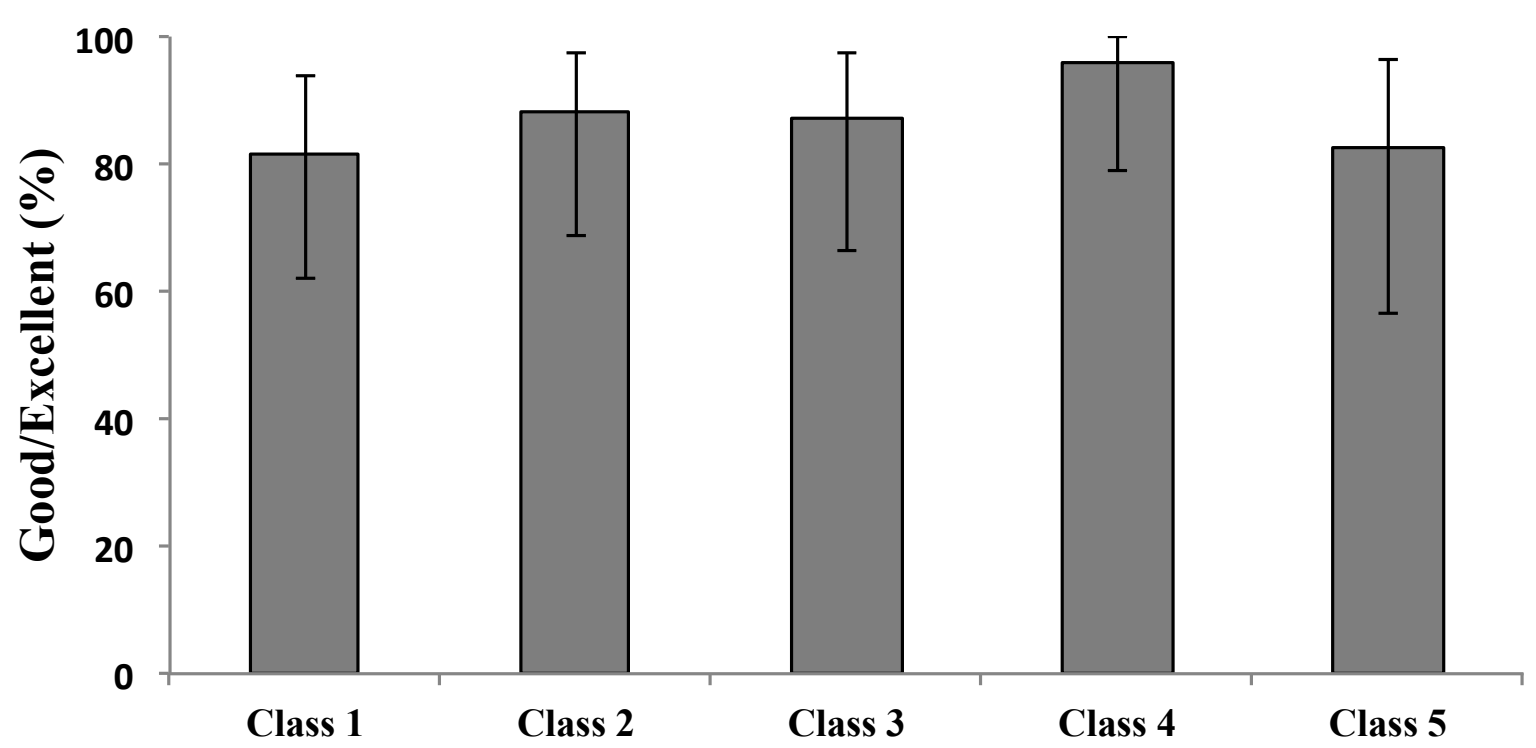

Figure 3. Behavior = changes in participants' on-the-job behavior because of training. 


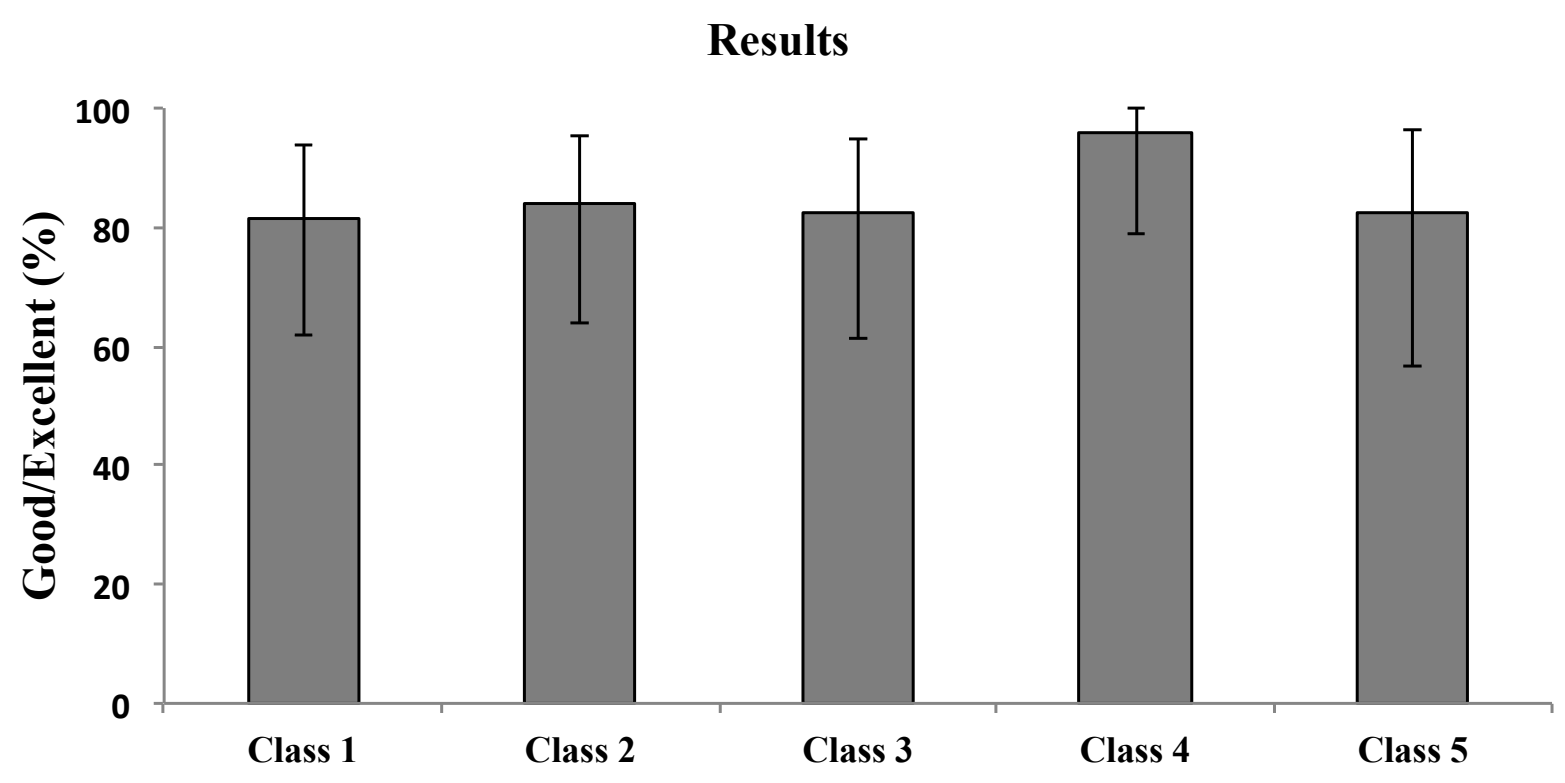

Figure 4 . Results $=$ final changes that occurred or may be possible due to training.

After the first two classes, as the expository lectures were gradually reduced in length, students started working on their projects, which involved metrics for pension plans, webpage design and management, personal finance plans, and recruitment and selection solutions. Neuroscience instruments that were applied included implicit measures such as the delay-discounting task to assess impulsivity behavior as a metric to support selection of people in the consulting firm.

\section{Discussion and Conclusion}

The general aim of this study was evaluate the implementation of an extension course in Applied Neuroeconomics, using Kirkpatrick's four-level model (Kirkpatrick, 1998). Our results indicated that the extension course had an impact on students' perceptions of the adequacy and applicability of the course content for consulting purposes, thus confirming our hypothesis. Although any attempt at interpretation may seem speculative, our findings also suggest that the program was well-structured and provided neuroscientific content and basic psychological literacy, thus supporting practical value for students planning careers in economics and management consulting.

Additionally, these process evaluation results indicated the relevance of analyzing each class's contributions separately. By taking this approach, it was possible to note the variation in the students' perceptions in the first two categories (i.e., reaction and learning). One possible explanation for the variation could be that the novelty had diminished after the program progressed. Another reason could be that in the third class, the learning responsibility shifted greatly from the teacher to the students, who had to work more closely on their applied projects and prepare for their oral presentations.

With regards to the evaluation method implemented, Kirkpatrick's model (Kirkpatrick, 1998) 
was considered appropriate for assessing the quality of the program. It was very easy to apply, and the students had no problem understanding the instrument. We highlight its relevance in measuring the impact of educational programs as it provides helpful information for future interventions. The evaluation process itself also helps the instructors to follow the course purposes. Future evaluations could also benefit from combining both process and content assessments.

Based on the positive feedback obtained from the process evaluation, the Applied Neuroeconomics extension course was reedited, and a second edition was conducted at UFRGS one semester later. There was also a seminar introducing the program, which brought together more than 100 students. Several students expressed their interest in learning about neuroeconomics, and some started volunteering in research activities and became involved in research initiation programs. Preliminary versions of this study were presented at the 43rd Society for Neuroscience Annual Meeting in San Diego, California (United States) as well as at the 6th meeting of the Brazilian Institute of Neuropsychology and Behavior (Institute Brasileiro de Neuropsicologia e Comportamento - IBNeC) in São Paulo (Brazil). The authors especially thank the former for the merit award achieved.

\section{Acknowledgments}

We thank the student members of the Equilíbrio Junior Consulting Firm (board of directors 2012-13) for their cooperation. We thank the research students Daniel Engel, Gibson J. Weydmann, and Ricardo R. Santolim for their data tabulation assistance, and the psychology graduate office staff for their registration operations. We also thank the Coordination for the Improvement of Higher Education Personnel (CAPES) for their financial support.

\section{References}

Arthur, W., Bennett, W., Edens, P.S., \& Bell, S.T. (2003). Effectiveness of training in organizations: A meta-analysis of design and evaluation features. Journal of Applied Psychology, 88, 234-245. https://doi.org/10.1037/0021-9010.88.2.234

Camerer, C.F. (2013). A review essay about foundations of neuroeconomic analysis by Paul Glimcher. Journal of Economic Literature, 51, 1155-1182. https://doi.org/10.1257/jel.51.4.1155

Camerer, C.F., Loewenstein, G., \& Prelec, D. (2004). Neuroeconomics: Why economics needs brains. Scandinavian Journal of Economics, 106, 555-579.

Cowan, J.A., \& Devine, C.M. (2012). Process evaluation of an environmental and educational nutrition intervention in residential drug-treatment facilities. Public Health Nutrition, 15, 1159-1167. https://doi.org/10.1017/S1368980012000572

Fehr, E., \& Rangel, A. (2011). Neuroeconomic foundations of economic choice: Recent advances. Journal of Economic Perspectives, 25(4), 3-30. https://doi.org/10.1257/jep.25.4.3

Glimcher, P.W., \& Rustichini, A. (2004). Neuroeconomics: The consilience of brain and decision. Science, 306, 447-452. https://doi.org/10.1126/science.1102566 


\section{Macrothink}

Journal of Management Research

ISSN 1941-899X

2017, Vol. 9, No. 1

Kirkpatrick, D. (1998). Evaluating training programs: The four levels. San Francisco: Berrett-Koehler Publishers.

Loewenstein, G., Rick, S., \& Cohen, J.D. (2008). Neuroeconomics. Annual Review of Psychology, 59, 647-672. https://doi.org/10.1146/annurev.psych.59.103006.093710

Praslova, L. (2010). Adaptation of Kirkpatrick's four level model of training criteria to assessment of learning outcomes and program evaluation in higher education. Educational Assessment Evaluation and Accountability, 22(3), 215-225. https://doi.org/10.1007/s11092-010-9098-7

Quartz, S.R. (2008). From cognitive science to cognitive neuroscience to neuroeconomics. Economics and Philosophy, 24, 459-471. https://doi.org/10.1017/S0266267108002083

Simpson, J.S., \& Scheer, A.S. (2016). A review of the effectiveness of breast surgical oncology fellowship programs utilizing Kirkpatrick's evaluation model. Journal of Cancer Education, 31, 466-471. https://doi.org/10.1007/s13187-015-0866-4

Tian, Y.L., Hu, L., Jiao, Y., Luo, M.Q., \& Wu, G.H. (2015). Evaluation of simulation-based training for aircraft carrier marshalling with learning cubic and Kirkpatrick's models. Chinese Journal of Aeronautics, 28(1), 152-163. https://doi.org/10.1016/j.cja.2014.12.002

Volk, S., \& Kohler, T. (2012). Brains and games: Applying neuroeconomics to organizational research. Organizational Research Methods, 15, 522-552. https://doi.org/10.1177/1094428112449656

Wu, B., Hu, Y.L., Gu, X.Q., \& Lim, C.P. (2016). Professional development of new higher education teachers with information and communication technology in Shanghai: A Kirkpatrick's evaluation approach. Journal of Educational Computing Research, 54, 531-562. https://doi.org/10.1177/0735633115621922

Zak, P.J. (2004). Neuroeconomics. Philosophical Transactions of the Royal Society B-Biological Sciences, 359, 1737-1748. https://doi.org/10.1098/rstb.2004.1544 